\title{
MODELLING OF FINANCIAL RESOURCE ALLOCATION FOR INCREASING THE SUPPLY CHAIN RESILIENCE USING MARKOV CHAINS
}

\author{
Martin Čech \\ VSB - Technical University of Ostrava, 17. Listopadu 2172/15, 70800 Ostrava, Czech Republic, EU, \\ martin.cech@vsb.cz (corresponding author) \\ Radim Lenort \\ VSB - Technical University of Ostrava, 17. Listopadu 2172/15, 70800 Ostrava, Czech Republic, EU, \\ radim.lenort@vsb.cz
}

Keywords: supply chain resilience, resource allocation, modelling, Markov chains

Abstract: The concept of supply chain resilience has arisen in response to changing conditions in the global market environment. Although supply chain resilience building is gaining increasing interest among the professional public and business practice, supporting decision-making in supply chain resilience building is still in its infancy. This article aims to present a mathematical model of the supply chain based on Markov chains to assess the impact of funds allocated to strengthening the supply chain's resilience to its overall performance and thus support decision-making in the field. Mathematical model assumptions are presented, then a mathematical model of a linear supply chain is developed and generalized, tested and methodological recommendations are presented. To support the use of the model, a set of managerial implications is presented, benefits and limitations are discussed, and further research direction is defined.

\section{Introduction}

The current market environment, which its everincreasing complexity and globalization can characterize, is invariably subject to heightened instability and sudden changes. The environment thus becomes turbulent and leads to gradually increasing demands on management processes. This leads to an increased emphasis on logistical management and optimization in the broadest possible interpretation of these notions across the whole supply chain. It is no longer possible to only optimize processes inside a managed company, but it is also important to look beyond the boundaries of the company, towards its suppliers and customers, and assess company management from the viewpoint of its incorporation into a complex system of interconnected entities. One of the latest concepts reacting to these needs is the notion of the resilience of supply chains. The contemporary importance of supply chain resilience is also confirmed by the BCI Supply Chain Resilience Report 2018 [1] of the Business Continuity Institute. The motivation for the submitted research work is to help answer questions arising in the area of the strategic management of supply chains, and specifically related to building up their resilience: "Which parts of an industrial supply chain should receive financial resources in order to increase resilience and how many financial resources should be allocated for this purpose in order to maximize the resulting economic impact?" The aim is to lay the foundations for a mathematical model based on Markov chains which will facilitate the comparison of the impacts of different allocations of financial resources onto increasing the resilience of individual parts of the supply chain.

\section{Supply chain resilience and disruptions}

The notion of resilience focuses on the requirement that supply chains should be able to withstand changes in a turbulent, unstable environment and building up resilience is based on a perception of changes in a business environment and disruption risks. These risks may be divided into several basic categories, notably including internal risks and external risks for the company and external risks for the supply chain [2]. The central principle for the building up of resilience is the reduction or removal of the vulnerability of supply chains towards possible disruptions; this is naturally based on a concrete understanding of such risks. Resilience is then understood as the ability of a supply chain to return to its original condition after an unexpected disruption [3].

Disruption of a supply chain is defined as a reduction of its output, or a complete breakdown of its elements or the supply chain as a whole, as a consequence of an internal or external event. Based on the World Economic Forum [4], we may define five primary sources of disruptions: natural disasters, extreme weather, political conflicts and problems, terrorism, and sudden radical changes in demand.

Building up resilience is a strategic goal that requires active collaboration between all involved parts of the chain and the exertion of substantial financial resources. Resilience is built up by improving the capabilities of the supply chain, which notably include the flexibility of 
MODELLING OF FINANCIAL RESOURCE ALLOCATION FOR INCREASING THE SUPPLY CHAIN RESILIENCE USING MARKOV CHAINS

Martin Čech; Radim Lenort

obtaining resources or handling of orders, capacity, efficiency, visibility, adaptability, prediction, restoration, dispersion, collaboration, organization, market strength, security and financial strength [5]. Currently, the capabilities required for building up the resilience of supply chains have been studied by a number of authors, often presenting significant differences in their interpretation of how these capabilities can be improved [6$11]$.

\section{Supply chain resilience modelling}

Ribeiro and Barbosa-Povoa [12] summarized contemporary quantitative approaches used to model the resilience of supply chains in their study from 2018, in which they analyzed nearly 40 recent scientific publications and presented a survey of this area. The authors emphasized the importance of finding an unambiguous definition of resilience and focusing future research on the development of quantitative methods for evaluating and building up resilience from a global perspective rather than assessing the individual components of supply chains.

There is a range of specialized studies that focus on modelling supply chain disruptions, especially from the area of operations research and management. Here we can mention, for instance, the exhaustive study of Snyder et al. [13], which surveys the state of the area. Based on the analyzed articles, the authors list several fundamental findings and recommendations for future research in this area:

- $\quad$ Rejection of risk - most models primarily focus on disruptions that occur infrequently, and decisionmaking is expected to be carried out from a neutral position. In practice, this may lead to the rejection of risks and a focus on optimizing non-key parameters.

- Estimation of input parameters - historical data on disruptions of supply chains are very rare, and an estimation of the input parameters is hence very complex. Most models, however, use the assumption that parameters can be determined or estimated with high confidence. One of the main directions for future research should thus be the development of techniques for the reliable estimation of the parameters of disruptions or models which work well without such data.

- Proactive and reactive strategies - a large portion of the introduced models focus on finding an optimal strategy for dealing with disruptions. Most models consider either proactive measures or a reactive strategy that can be used once a disruption is identified. Future research should also focus on models that can simultaneously support both of these responses.

The approaches for modelling resilience are prominently shaped by the simulation introduced by Grakova [14] in her $\mathrm{PhD}$ thesis. There, she defines the basic steps that need to be taken in order to efficiently use simulation software for identifying key elements of a supply chain and comparing various schemes for allocating financial resources in order to increase the resilience of a supply chain. The work follows up on preceding research that attempted to simulate the behaviour of supply chains, situated primarily in the area of risk management for supply chains.

Another simulation study has been authored by Falasca et al. [9], who define three basic factors that impact the resilience of a supply chain - its structure, complexity and the criticality of individual elements - and propose a methodology for creating simulation models and scenarios of simulation experiments. Carvalho et al. [15] introduce a simulation model for a supply chain that evaluates the supply time and overall costs as the basic output parameters used to assess the resilience of a supply chain in the automotive area. Nunes et al. [16] expand the previous model with an application of fuzzy set theory and analyze the impact of supply chain disruptions and of the measures adopted to reduce the impacts of such disruptions.

\section{Research gap identification}

Our current understanding of the area of supply chain resilience clearly indicates that up to now, research primarily focused on finding a definition of resilience and a subsequent evaluation of the amount of resilience of a supply chain. As far as building up resilience is concerned, the studies carried out to date consider mostly general and qualitative recommendations for resilience built-up, while the actual measurement of resilience is still in its infancy there is no unified methodology for such measurements, and in general, the topic has not attracted much attention among scientists in the field. This means that the management of industrial supply chains can receive qualified recommendations about, e.g., which key skills of the supply chain they should focus on and what to aim for when trying to improve these. However, the possibilities for supporting decision-making processes in the area of allocating funding for resilience build-up have not been covered by research to date; this fact has also been noted by Rice [17].

One of the prominent advances in the area of decisionmaking support for resilience build-up in view of the efficient utilization of financial resources is attributed to Grakova [18], whose PhD thesis focused on the use of simulations. A prerequisite for her approach is a sufficient understanding of the selected simulation tool. Another disadvantage of the simulation approach is the relatively high time requirement: in order to evaluate the carried-out experiments, it is necessary to carry out a statistically sufficient number of independent experiments, and moreover, it is not possible to simulate too many schemes for financial resource allocation. In view of these facts, Grakova proposed the use of experiments designed based on DOE (Design of Experiments) principles. On the other 
hand, the use of DOE significantly restricts the number of parts that can be included in the simulated supply chain.

The aim of this article is to build on state of art in the area of supply chain resilience build-up and introduce a mathematical model that allows us to answer the question of which part of a supply chain should receive financial resources in order to increase the chain's resilience so that the economic impact of such an investment is maximized to ensure the efficient use of the financial resources. The introduction of the mathematical model opens up new possibilities for building up the resilience of supply chains precisely in this area.

\section{$5 \quad$ Modelling of stochastic systems using Markov chains}

A Markov Chain typically describes a discrete stochastic process with the core feature that the probability of transitioning to another state depends only on the current state and not on previous states. This property of the investigated system is called the Markov property and allows the behaviour of the studied system to be depicted as a state graph. The abstract notion of a stochastic process [19] can be used to describe random phenomena which are a function of time. Examples of stochastic processes can be found across many scientific disciplines and also in numerous real-life situations. The mathematical theory behind Markov chains used to create the mathematical model is based on literature dedicated to this topic [19-21].

For the purposes of this article, we hereinafter only consider real random variables, even though the theory of stochastic processes also analogously defines complex random processes. The modelled system is characterized as a stochastic process with a discrete notion of time and discrete states, where random variables are only assigned discrete values and where the stochastic processes range over independent values. For the purposes of this article, we hereinafter consider only homogeneous Markov chains.

\section{A Model supporting decision-making when building up supply chain resilience based on Markov chains}

The following paragraphs introduce a mental map of the studied problem, specify the prerequisites and define the input parameters of the mathematical model. The theory of Markov chains is then used to create a mathematical model for supply chains consisting of two chains in a supplier-consumer relationship, which is then generalized to support an arbitrary number of linearly interconnected chains.

\subsection{Mental map}

A supply chain is viewed as a system of seriesconnected entities (parts) of the chain, which assume the roles of suppliers and customers. The idea is to look at chains from a global context, where individual parts operate in distinct regions - meaning not necessarily geographically separated regions, but also, for instance, regions that are separate from an economic, political or cultural standpoint. Individual regions can be analyzed in terms of their entrepreneurial environment, and this can serve as a basis for an estimation of the nature of possible disruptions, the probabilities of their occurrence or the time required to remove the consequences of such unexpected events. The considered supply chains are capacity-neutral, and a part in a chain that follows a preceding part can process precisely the number of inputs that the preceding part produces. The maximum capacity of individual parts is reduced due to the occurrence of significant disruptions, leading to the possible loss of parts or a reduction of the capacity of individual parts until the consequences of the disruption are removed. No part of the supply chain can stockpile its output, and hence the reduced capacity will be felt immediately once disruption occurs. Next, this mental map is transformed into a set of requirements for the mathematical model.

\subsection{Requirements for the mathematical model}

The following subsections summarize the requirements for the mathematical model with respect to the structure and operation of the investigated supply chain and its individual parts, the properties of the considered disruptions, their impacts and possible ways of reducing said impacts. The set of requirements for the mathematical model is based on an abstraction of a supply chain and the requirements form the foundation for the mathematical model.

\subsubsection{Logistical requirements}

- A supply chain is a system of interconnected links linked with supplier-customer relations.

- A part of a supply chain represents a set of suppliers or customers operating in a single region.

- The supply chain is series-connected (linear).

- The supply chain is capacity-neutral. There is no stockpiling.

- The supply chain cannot be blocked by-products that are awaiting processing during a disruption.

- Disruptions occur randomly and affect individual links operating in distinct regions, whereas the mean time between disruptions and the mean duration is random variables characterized by an exponential distribution.

- All parts of a supply chain may be affected by a disruption, even simultaneously.

- It is possible to identify the Mean Time Between Failure (MTBF) and Mean Time to Recovery (MTTR) for each part of the supply chain.

- The MTBF is greater than the MTTR.

- The resilience of the supply chain, and specifically its individual parts, can be increased by allocating financial resources. 
MODELLING OF FINANCIAL RESOURCE ALLOCATION FOR INCREASING THE SUPPLY CHAIN RESILIENCE USING MARKOV CHAINS

Martin Čech; Radim Lenort

- The increased resilience of the supply chair, and specifically its individual parts, leads to a reduced MTTR, but does not affect the MTBF (in line with the adopted definition of resilience).

- It is possible to determine, for each part of the supply chain, the functional dependence of the MTTR on the number of financial resources allocated to the given part with the aim of increasing its resilience.

- The MTTR has an indirect linear dependence on the amount of allocated financial resources.

- For each part of the supply chain, it is possible to determine the minimum amount of financial resources that are required to start increasing its resilience.

- The attributes (and hence the values of input parameters) of individual parts of the supply chain are obtainable (e.g., via an expert report or from an analysis of the business environments and internal potentials of individual articles).

\subsubsection{Methodological requirements}

- The supply chain can be viewed as a Markov process with discrete time steps.

- The output of the supply chain can be estimated based on stationary probability distributions specified for the system at its individual designated states, calculated based on the theory of Markov processes.

- Due to the use of Markov processes with discrete time steps, the MTTR cannot be reduced beyond the value of 1 step.

- It is possible to find a solution for the task of allocating financial resources for increasing the resilience of individual parts of the supply chain that will ensure the maximum possible increase of the overall output of the supply chain after deducting the total allocated financial resources in the modelled period.

- The time dimension is implicitly included in the model as a parameter of the maximum output of the supply chain. This output is specified as an input parameter of the model and is represented via the economic performance of the supply chain over the modelled period.

- The model should be used to support strategic decision-making, whereas the modelled period refers to a time period that the given supply chain considers being of strategic importance for its operations.

\subsubsection{Economic requirements}

- The output of a supply chain whose resilience has not been increased (the original output) is represented by the cumulative economic output of all parts over the modelled period.

- The output of a supply chain after its resilience has been increased is represented by the cumulative economic output of all parts over the modeled period after their resilience has been increased via the allocation of financial resources.

- The increased output of a supply chain after its resilience has been increased is defined as the output of the supply chain with increased resilience minus the original output of the supply chain and additionally minus the total financial resources allocated to increasing the chain's resilience.

- Allocated financial resources represent any and all costs exerted into increasing the resilience of the supply chain.

- Disruptions lead to a relative reduction of the output of the affected part of the supply chain (e.g., to $20 \%$ of the full output of the given part).

\subsection{Creation of the Mathematical Model}

Below, we define the input parameters of the mathematical model and derive a mathematical model for linearly structured supply chains with two parts in a supplier-customer relationship, which is then generalized for linear supply chains consisting of $n$ parts $(i=$ $1,2, \ldots, n)$.

\subsubsection{Input parameters of the mathematical model}

Based on the above-mentioned mental map following input parameters of the mathematical model are defined:

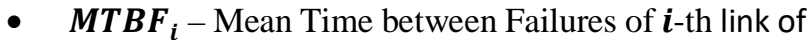
the supply chain (days),

- $\quad \boldsymbol{M T T} \boldsymbol{R}_{\boldsymbol{i}, \mathbf{0}}$ - initial Mean Time to Recovery of $\boldsymbol{i}$-th link of the supply chain with no funds allocated to improve the links' resilience (days),

- $\boldsymbol{I}_{\boldsymbol{i} \text {,min }}$ - the minimum amount of financial allocation, which will lead to an increase in the resilience of the $\boldsymbol{i}$-th link in the supply chain (EUR),

- $\quad I_{i, \max }-$ the number of funds needed to fully eliminate the effects of disruption of $\boldsymbol{i}$-th link in the supply chain (EUR),

- $\quad \boldsymbol{I}_{\boldsymbol{i}}$ - allocation of funds to increase the resilience of the $\boldsymbol{i}$-th link in the supply chain (EUR),

- $\boldsymbol{V}_{\boldsymbol{i} \text {,NOK }}$ - relative performance of the $\boldsymbol{i}$-th link in the supply chain at the time of operation under disturbance (\%),

- $\boldsymbol{V}_{\max }-$ maximal performance of the supply chain in a modelled period without any disturbance (EUR),

- $\quad I_{\max }$ - the maximum amount of the sum of all funds allocated in individual supply chain links (EUR)

- $\boldsymbol{i}=\mathbf{1}, \mathbf{2}, \ldots, \boldsymbol{n}$ - the designation of the $\boldsymbol{i}$-th supply chain link, where $\boldsymbol{n}$ is the number of links of the supply chain,

- Supply chain structure defined by the directed acyclic graph. 


\section{MODELLING OF FINANCIAL RESOURCE ALLOCATION FOR INCREASING THE SUPPLY CHAIN} RESILIENCE USING MARKOV CHAINS

Martin Čech; Radim Lenort

\subsubsection{A Mathematical model for a supply chain with two parts}

Let a "scheme" be a specific allocation of the financial resources to individual parts of the supply chain. Then, by determining how the output increased after the resilience was increased via various schemes, it will be possible to compare these schemes and choose the best one. Here, the best scheme is one that, based on the problem setup, provides the supply chain as a whole with the best economic effect, i.e., a scheme which maximizes the difference between the supply chain's output after applying the scheme and the supply chain's output without any scheme minus the sum of allocated financial resources. The function we want to optimize is thus defined by the following formula (1):

$$
Z_{\max }=V_{\mathrm{I}}-V_{0}-\sum_{i=1}^{n} I_{i}
$$

where:

$V_{\mathrm{I}}$ is supply chain performance after increasing the resilience via a specific scheme of allocation of available funds between individual supply chain links (EUR),

$V_{0}$ is original performance of the supply chain in a modelled period (EUR),

$n$ is the total number of links in the supply chain,

$I$ is $I=\left(I_{1}, I_{2}, \ldots, I_{n}\right)$ specific distribution of financial resources between individual links in the supply chain, the so-called "scheme" (EUR),

$I_{i}$ is the number of funds allocated to increase the resilience of the $i$-th link of the supply chain for $i=1, \ldots, n$ (EUR).

Determining the value of the optimization function requires the performance of certain calculations. The total financial resources allocated to increasing the resilience of the supply chain can be calculated as a simple sum of all resources allocated to individual parts, i.e. $\sum_{i=1}^{n} I_{i}$. Based on the specified requirements, the following constraint must be satisfied (2):

$$
\sum_{i=1}^{n} I_{i} \in\left\langle 0 ; I_{\max }\right\rangle
$$

where $I_{\max }$ is the maximum sum over all allocated financial resources.

In order to determine the output of the supply chain after its resilience has been increased via the allocation of financial resources amounting to $I_{i}$ for individual links and its original output without any allocated financial resources, the behaviour of the considered supply chain is modelled as a Markov chain.

Below, we derive the mathematical model for a supply chain consisting of two links (see Figure 1, where "SCL" refers to individual links). This is then generalized to $n$ links in Subsection 6.3.3.

Given the requirements specified above, the behaviour of the supply chain can be viewed as a Markov process, i.e., a sequence of random integers $\left\{X_{\tau}, \tau \in \mathbb{N}\right\}$ in a defined probability space $(\Omega, A, P)$. Let $S$ be a finite set of states of the random process $\left\{X_{\tau-1}, \tau \in \mathbb{N}\right\}$ and let its elements be the states of this process. For each part of the supply chain and at each time point, there are two states that it could lie in:

- $\quad$ the $i$-th link is fully operational,

- $\quad$ the $i$-th link is disrupted.

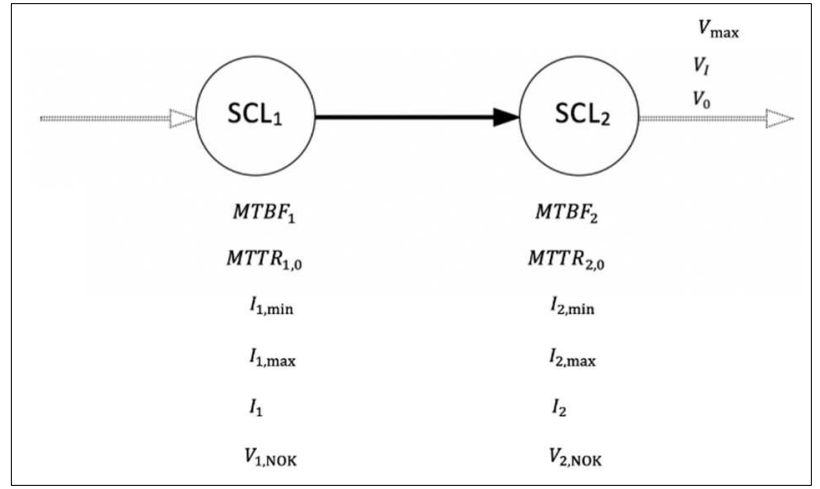

Figure 1 Scheme of a supply chain of a linear structure consisting of two supply chain links

The states of the individual parts can be identified by a binary digit, where 1 means that the $i$-th part is operational and 0 that it is disrupted. It is thus possible to define and label all possible states that the modelled supply chain could reach over time, see Table 1 . The code for the state of the supply chain can be expressed via a binary number $c$ consisting of $n=2$ (where $n$ is the number of parts of the supply chain) digits $c_{k}$, as follows (3):

$$
c=\sum_{k=0}^{n-1} c_{k+1} \cdot 2^{k}=c_{2} \cdot 2^{1}+c_{1} \cdot 2^{0}
$$

where:

$$
c_{1}, \ldots, c_{n} \in\{0,1\}
$$

Table 1 Possible supply chain states

\begin{tabular}{|c|c|c|c|l|}
\hline $\begin{array}{c}\text { Supply } \\
\text { chain } \\
\text { state }\end{array}$ & $\begin{array}{c}\text { State of } \\
\mathbf{S C L}_{\mathbf{1}}\end{array}$ & $\begin{array}{c}\text { State of } \\
\mathbf{S C L}_{\mathbf{2}}\end{array}$ & $\begin{array}{c}\text { Code of supply } \\
\text { chain state }(\boldsymbol{c})\end{array}$ & \multicolumn{1}{|c|}{ State description } \\
\hline 0 & 0 & 0 & 00 & Both links disrupted. \\
\hline 1 & 0 & 1 & 01 & Link SCL $\mathrm{SC}_{1}$ disrupted, link SCL $\mathrm{Sull}_{2}$ operational. \\
\hline 2 & 1 & 0 & 10 & Link $\mathrm{SCL}_{1}$ fully operational, link $\mathrm{SCL}_{2}$ disrupted. \\
\hline 3 & 1 & 1 & 11 & Both links fully operational. \\
\hline
\end{tabular}


The supply chain consists of 4 states. Hence, let $S=$ $\{0,1,2,3\}$ be the set of all states of the supply chain, viewed as a Markov process. The Markov process describing the behaviour of this system can be visualized as a graph, where the nodes represent individual states and edges represent the transitions between states with the appropriate transition probabilities $p_{c d}$, see Figure 2 .

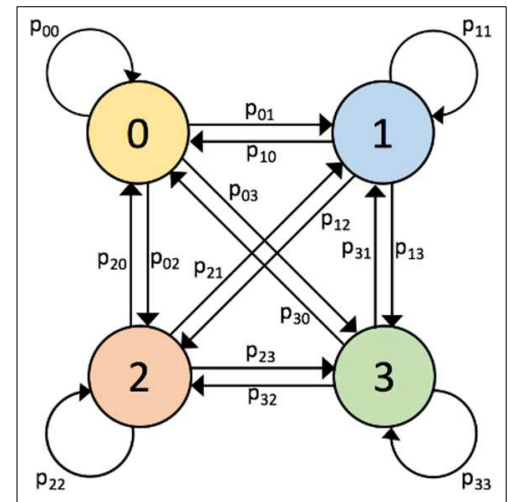

Figure 2 Graph of Markov chain of the modelled supply chain of two links

For the considered supply chain, viewed as a stochastic process and/or a homogeneous Markov chain, Markov theory states that it is possible to create a regular matrix $\boldsymbol{P}$ (4) of transition probabilities between individual states. In our case, this will be a $4 \times 4$ matrix:

$$
\boldsymbol{P}=\left\{p_{c d}\right\}
$$

where:

$c=0,1,2,3$ is initial supply chain state,

$d=0,1,2,3$ is following the supply chain state.

The following paragraphs explain the formulas for computing the probabilities $p_{c d}$ of transitions between an initial state c and a following state $d$ of the supply chain, and how these are obtained. In order to determine the transition probabilities $p_{c d}$, it is necessary to consider the probabilities of state changes for individual parts of the supply chain when their state changes.

As was described above, each part (in a specific region) of the considered and modelled supply chain exhibits a linear dependency of the MTTR (defined only within the interval $\left\langle I_{i, \min } ; I_{i, \max }\right\rangle$, where $\left.i=1,2\right)$ on the number of financial resources allocated to increase the resilience of the given part. This linear dependence is depicted in Figure 3 .

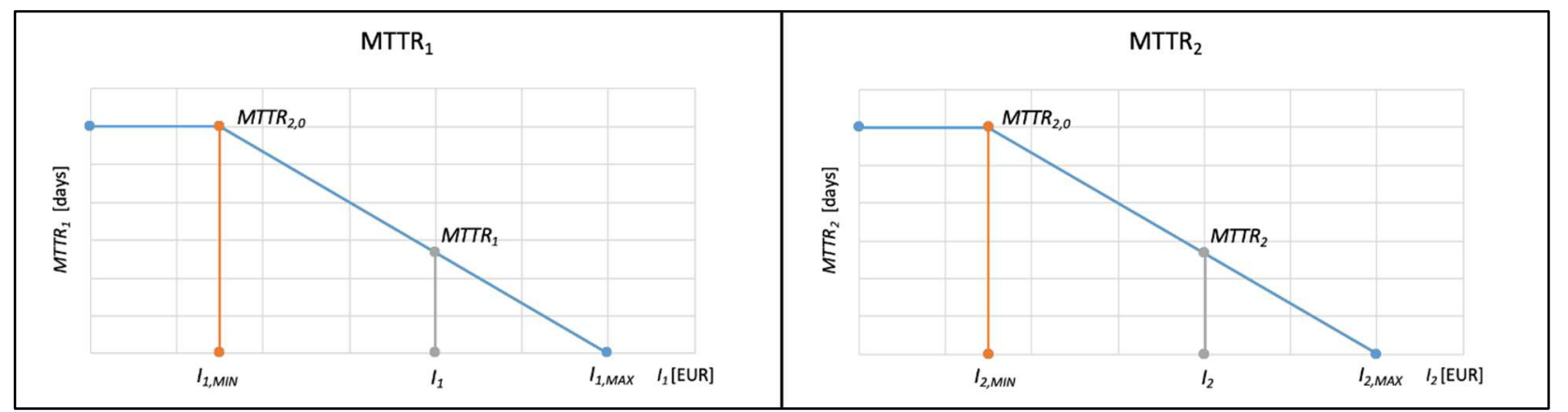

Figure 3 Linear dependency of the meantime to the recovery of two supply chain links on the number of financial resources allocated to increase their resilience

Using the general equation for a line, the $M T T R_{i}$ (i.e., the meantime to repair for the $i$-th part) when financial resources in the amount of $I_{i}$ were allocated to increase the resilience of that part, can be captured by an equation (5) that uses previously defined input parameters of the model:

$$
\operatorname{MTTR}_{i}=\left\{\begin{array}{cl}
\operatorname{MTTR}_{i, 0} & , \text { if } I_{i} \in\left\langle 0, I_{i, \text { min }}\right\rangle, \\
\frac{\operatorname{MTTR}_{i, 0} \cdot\left(I_{i}-I_{i, \mathrm{max}}\right)}{I_{i, \mathrm{~min}}-I_{i, \text { max }}} & , \text { if } I_{i} \in\left(I_{i, \text { min }}, I_{i, \text { max }}\right\rangle, \\
0 & , \text { if } I_{i}>I_{i, \text { max }},
\end{array}\right.
$$

Within the context of the studied problem and for the modelled supply chain, the relation defined above can only be used if the following conditions are met:

$$
\begin{gathered}
0 \leq I_{i, \min } \leq I_{i}<I_{i, \max } \\
\operatorname{MTTR}_{i, 0}>0
\end{gathered}
$$

For each part, it is now possible to determine a frequency for the repair of that part, denoted by $\mu_{i}(6)$ this represents the probability of transitioning from state " 0 " to state " 1 ": 
MODELLING OF FINANCIAL RESOURCE ALLOCATION FOR INCREASING THE SUPPLY CHAIN RESILIENCE USING MARKOV CHAINS

Martin Čech; Radim Lenort

$$
\mu_{i}=\frac{1}{M T T R_{i}}
$$

The input parameter capturing the mean time between failures, $M T B F_{i}$, (7) can be used to derive the frequency of disruption for each part $\lambda_{i}$, which represents the probability of transitioning from state " 1 " to state " 0 ":

$$
\lambda_{i}=\frac{1}{M T B F_{i}}
$$

Based on the behaviour of the modelled supply chain and the states described above, which capture the states of individual parts and hence also the supply chain as a whole, it is possible to derive a probability $\mu_{i}^{\prime}(8)$ for each part that captures the likelihood that the $i$-th part will remain disrupted when transitioning from a state where that part is disrupted to the next state:

$$
\mu_{i}^{\prime}=1-\mu_{i}=1-\frac{1}{\operatorname{MTTR}_{i}}
$$

Similarly, for each part, it is possible to determine the probability $\lambda_{i}^{\prime}$ (9) that captures the likelihood that the $i$-th part will remain fully operational when transitioning from a state where that part was fully operational:

$$
\lambda_{i}^{\prime}=1-\lambda_{i}=1-\frac{1}{M T B F_{i}}
$$

Based on findings from the theory of bulk processing and the reliability theory, a so-called system stabilization condition has been adopted, which states that $\lambda_{i}<\mu_{i}$. This condition fully complies with our understanding of disruptions within the concept of resilience applied to supply chains and their parts. In particular, disruptions are understood to refer to events that are infrequent, with an MTBF ranging in years, while their duration (MTTR) is significantly lower - days or months.

Next, the aforementioned formulas capturing the probabilities of state changes for individual parts when the Markov chain modelling supply chain undergoes a state transition are used to create formulas for calculating the transition probabilities $p_{c d}$, which are needed to construct the matrix containing the probabilities of transitions between individual states of the Markov chain, previously defined as $\boldsymbol{P}$. The formulas for calculating individual probabilities $p_{c d}$ are constructed via the binary representation of the states of the supply chain as defined above. The binary number $c$ represents the original state of the supply chain, while the binary number $d(10)$ represents the following state of the supply chain:

$$
d=\sum_{k=0}^{n-1} d_{k+1} \cdot 2^{k}=d_{1} \cdot 2^{0}+d_{2} \cdot 2^{1}
$$

where:

$$
d_{1}, \ldots, d_{n} \in\{0,1\}
$$

The probability $p_{c d}(11)$ for transitioning from state $c$ to state $d$ can then be determined as follows:

$$
p_{c d}=q_{1} \cdot q_{2}
$$

where $q_{k}=\left\{\begin{array}{l}\lambda_{i}, \text { if } c_{k}=1, d_{k}=0, \\ \mu_{i}, \text { if } c_{k}=0, d_{k}=1, \\ \mu_{i}^{\prime}, \text { if } c_{k}=d_{k}=0, \\ \lambda_{i}^{\prime}, \text { if } c_{k}=d_{k}=1,\end{array}\right.$

for $k=1,2$.

The matrix $\boldsymbol{P}$ (12) with the transition probabilities created from the formulas derived above then has the following form:

$$
\boldsymbol{P}=\left(\begin{array}{ccc}
p_{00} & \cdots & p_{03} \\
\vdots & \ddots & \vdots \\
p_{30} & \cdots & p_{33}
\end{array}\right)
$$

In order to construct the transition probability matrix $\boldsymbol{P}$, Markov chain theory then shows that it suffices to solve the following system of equations (13), (14):

$$
\begin{gathered}
\boldsymbol{a P}=\boldsymbol{a} \\
\sum_{s=0}^{3} a_{s}=1,
\end{gathered}
$$

where

$\boldsymbol{P}$ is the matrix of transitions between individual states as defined based on the aforementioned relations,

$\boldsymbol{a}=\left(a_{0}, a_{1}, a_{2}, a_{3}\right) ; a \in \mathbb{R}^{n}$ is the stationary vector with the probabilities of the occurrence of individual states of the supply chain, where $a_{s}$ are the stationary probabilities of individual states of the supply chain for $s=0, \ldots, 3$.

For individual states of the supply chain, it is possible to use the probabilities $a_{s}$ of occurring in individual states computed in the previous calculation, along with the input parameters $V_{1, N O K}$ and $V_{2, N O K}$ specifying the relative output of individual parts when disrupted and the parameter $V_{\max }$ specifying the maximum possible output of a supply chain, to compute the outputs of the supply chain in individual states $V_{I}^{s}$ (states of the whole chain - compared to the states of parts - where the state occurs as the upper index). This $V_{I}^{S}$ is computed as a product of the probability $a_{s}$ that the supply chain will occur in the given state, the lowest relative output of a part $V_{i, N O K}$ if at least one part is disrupted within the given state $s$, and the maximum output of the supply chain in the modelled period without disruptions $V_{\text {max }}$, see Table 2 . 
MODELLING OF FINANCIAL RESOURCE ALLOCATION FOR INCREASING THE SUPPLY CHAIN RESILIENCE USING MARKOV CHAINS

Martin Čech; Radim Lenort

\begin{tabular}{|c|c|c|c|}
\hline \multicolumn{1}{c|}{$\begin{array}{c}\text { Table 2 Supply chain performance in individual states } \\
\text { Supply } \\
\text { stain } \\
(s)\end{array}$} & $\begin{array}{c}\text { Stationary } \\
\text { probability of state } \\
\left(a_{s}\right)\end{array}$ & $\begin{array}{c}\text { Supply } \\
\text { chain } \\
\text { state } \\
\text { code }\end{array}$ & $\begin{array}{c}\text { Supply chain performance in individual states } \\
\left(V_{I}^{s}\right)\end{array}$ \\
\hline 0 & $a_{0}$ & 00 & $V_{I}^{0}=a_{0} \cdot \min _{i=1,2} V_{i, \mathrm{NOK}} \cdot V_{\max }$ \\
\hline 1 & $a_{1}$ & 01 & $V_{I}^{1}=a_{1} \cdot V_{1, \mathrm{NOK}} \cdot V_{\max }$ \\
\hline 2 & $a_{2}$ & 10 & $V_{I}^{2}=a_{2} \cdot V_{2, \mathrm{NOK}} \cdot V_{\max }$ \\
\hline 3 & $a_{3}$ & 11 & $V_{I}^{3}=a_{3} \cdot V_{\max }$ \\
\hline
\end{tabular}

For all formulas used for calculating the output of the supply chain in individual states $V_{I}^{S}$, it holds that the input parameter of the relative output of a part during disruption $V_{i, N O K}$ is defined as a percentage of the output that the part achieves during a disruption. This means that $V_{i, N O K}$ ranges between 0 and 1 , and in other words, the calculation requires that $V_{i, N O K} \in\langle 0,1\rangle$.

The output $V_{I}$ (15) of the modelled supply chain with two parts, when financial resources in the amount of $I_{1}$ have been allocated to part $\mathrm{SCL}_{1}$ and in the amount of $I_{2}$ have been allocated to $\mathrm{SCL}_{2}$ with the aim of increasing resilience, can be determined as the sum of outputs of the supply chain calculated in the previous steps via the formula:

$$
V_{I}=\sum_{s=0}^{3} V_{I}^{s}
$$

In order to calculate the value $V_{0}(16)$ of the original output of the supply chain, i.e., when no financial resources have been allocated to increasing resilience, the same procedure as above has been used for $V_{I}$, but instead of calculating the $M T T R_{i}$ the calculation follows the formula:

$$
V_{0}=\sum_{s=0}^{3} V_{0}^{s}
$$

where $M T T R_{i}=M T T R_{i, 0}$. The formulas derived above can now be used to determine the value of the objective function for the allocation of financial resources to individual parts (in the amount of $I_{1}$ for part $\mathrm{SCL}_{1}$ and $I_{2}$ for part $\mathrm{SCL}_{2}$ ), as the output after increasing resilience minus the original output increased by the sum of allocated financial resources (17):

$$
Z_{\max }=V_{I}-V_{0}-\left(I_{1}+I_{2}\right)
$$

\subsubsection{A general mathematical model for a linear supply chain}

A general model for a supply chain where the parts in supply-customer relations are connected serially can be schematically depicted as in Figure 4.

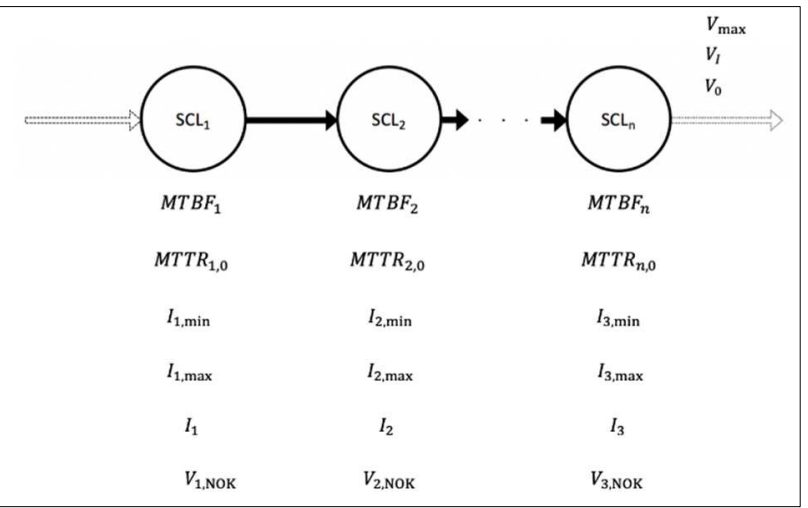

Figure 4 Scheme of a general model of linear supply chain

In order to create a general model for this setting, the core task is to construct the probability matrix that captures the probabilities of transitioning between individual states of the supply chain, i.e., the matrix denoted by $\boldsymbol{P}$. To do so, it is necessary first to define all the states in which the supply chain can lie.

The general number of elements of a set of states used to derive the general mathematical model for a linearly structured supply chain is $|\boldsymbol{S}|=2^{n}$, where $n \in \mathbb{N}$ is the number of parts of the modelled supply chain and the set of all states of the supply chain is $S=\left\{0,1,2, \ldots, 2^{n}-1\right\}$. Here, the matrix with the transition probabilities is more difficult for the geometrically increasing number of states due to the accompanying geometric growth of possible transitions between these states.

In order to construct the matrix $\boldsymbol{P}$ containing the transition probabilities $p_{c d}$ for transitioning from a state $c$ to the following state $d$, we shall express the original state as $c$ and the state after the transition as $d$, where these are binary numbers consisting of $n$ (which is the number of parts of the supply chain) digits $c_{k}$ based on the formulas (3) and (10) shown above. The transition probability $p_{c d}$ (18) for moving from state $c$ to $d$ can then be determined as follows:

$p_{c d}=q_{n} \cdot q_{n-1} \cdot \ldots \cdot q_{2} \cdot q_{1}$
where $q_{k}=\left\{\begin{array}{l}\lambda_{i}, \text { if } c_{k}=1, d_{k}=0, \\ \mu_{i}, \text { if } c_{k}=0, d_{k}=1, \\ \mu_{i}^{\prime}, \text { if } c_{k}=d_{k}=0, \\ \lambda_{i}^{\prime}, \text { if } c_{k}=d_{k}=1,\end{array}\right.$

for $k=1,2, \ldots, n$. 


\section{MODELLING OF FINANCIAL RESOURCE ALLOCATION FOR INCREASING THE SUPPLY CHAIN} RESILIENCE USING MARKOV CHAINS

Martin Čech; Radim Lenort

The transition probability matrix $\boldsymbol{P}$ can then be calculated by the parameters derived above (formulas 6-9). Next, we can once again determine the long-term stationary probabilities for the supply chain being in individual states via formulas 13 and 14.

In general, the output $V_{I}^{S}(19)$ of a supply chain with $n$ parts in individual states $S$ assuming linear connections is governed by:

$$
V_{I}^{s}=a_{s} \cdot \min _{i=1, \ldots n} V_{i}^{s} \cdot V_{\max }
$$

where

$$
\begin{gathered}
i=1,2, \ldots, n \\
s=0,1,2, \ldots, 2^{n}-1 .
\end{gathered}
$$

In order to compute the relative output $V_{i}^{s}$ of individual parts of the supply chain in a specific state, i.e., to determine $\min _{i=1, \ldots n} V_{i}^{S}$, it is possible to use a binary representation of the state of the parts in the state $s$ of the whole supply chain (20):

$$
\begin{gathered}
s=s_{n} \cdot 2^{n-1}+s_{n-1} \cdot 2^{n-2}+\cdots+s_{1} \cdot 2^{0} \\
=\sum_{k=0}^{n-1} s_{k+1} \cdot 2^{k}
\end{gathered}
$$

where

$$
s_{1}, \ldots, s_{n-1}, s_{n} \in\{0,1\}
$$

Then applies (21):

$$
V_{i}^{s}= \begin{cases}V_{i, N O K}, & \text { if } s_{k}=0 \\ 1, & \text { if } s_{k}=1\end{cases}
$$

In line with the logic underlying our calculations for two parts, the output $V_{I}$ of the supply chain in the model period (after the allocation of financial resources for building up resilience) can be calculated as (22):

$$
V_{I}=\sum_{s=0}^{2^{n}-1} V_{I}^{S}
$$

The calculation of the output $V_{0}$ of the original supply chain, i.e., with no additionally allocated financial resources, is then carried out analogously as for $V_{I}$, but instead of computing $M T T R_{i}$, the calculation uses the formula (23):

$$
V_{0}=\sum_{s=0}^{2^{n}-1} V_{0}^{s}
$$

Where we set $M T T R_{i}=M T T R_{i, 0}$.

The calculation of the objective functions for increasing resilience is once again carried out using the formula (1).

\subsubsection{The mathematical model calculation algorithm}

Based on the presented general mathematical model, the algorithm for calculating the mathematical model is described verbally below:

1. Defining the supply chain structure (assigning supply chain links to individual layers).

2. Enter input parameters for each link in the supply chain.

3. Specifying the maximum possible performance of the supply chain and the maximum possible amount of total funds to be allocated.

4. Specifying an allocation scheme.

5. Calculation of the transition probabilities between full operation and disturbance states for supply chain links.

6. Generate all possible supply chain states.

7. Calculation of the supply chain transition probability matrix.

8. Calculation of a stationary vector of supply chain probabilities of occurrence in individual states.

9. Calculation of supply chain performance in a particular tested scheme of allocation of funds and determination of the value of the objective function.

\section{Results and discussion}

The aim of the presented research was to introduce a mathematical model that allows us to support our ability to determine which part of a supply chain should receive financial resources designated for increasing resilience so as to maximize the economic effect, i.e., find the most efficient way of exerting available financial resources. The introduced mathematical model allows us to carry out experiments over serial-connected supply chains and compare various scenarios for the allocation of financial resources and their impacts on the resilience of the supply chain expressed via an increase of the overall output of the supply chain in the modelled period.

Individual elements of the model do not represent separate suppliers but rather a set of suppliers who operate in a single region that may potentially be affected by the same disruptions with a certain probability. The adopted approach, however, also allows the model to treat individual companies (or individual elements of the supply chain in greater detail) as elements. Choosing one or the other approach is based on the user's needs, but the specific choice needs to be taken into account when interpreting the results of the modelling and optimization processes. In order to determine the values of the input parameters that characterize the occurrence of disruptions, historical data that could be used to statistically determine this is typically not available. In order to set these values, instead of using prediction methods based on an analysis of historical data, one can recommend the use of forward-oriented prognostic methods focusing, for example, on an analysis of the business environment, political and economic development, etc. The setup of functional dependencies for 
MODELLING OF FINANCIAL RESOURCE ALLOCATION FOR INCREASING THE SUPPLY CHAIN RESILIENCE USING MARKOV CHAINS

Martin Čech; Radim Lenort

increasing resilience and the minimum as well as a maximum admissible allocation for individual parts is up to the user.

When interpreting the results of experiments carried out over the model, one needs to pay increased care since these will only be of a quality that corresponds to the quality of the input data. In order to obtain a clearer idea of the possibility for increasing the resilience of a supply chain, the scheme for allocating financial resources and the effort exerted in improving individual parts, it is recommended to perform a large number of experiments. This can be used to ascertain whether there exist multiple key parts where allocations have a similar effect, and this information could then be used in combination with other findings about the supply chain, e.g. which parts can the management improve more easily or via additional resources.

\section{Conclusions}

The introduced model pushes the frontiers of scientific knowledge in the area of support for decision-making when building up the resilience of supply chains. The model allows interested persons working in the area and/or from business practice to perform experiments. The fundamental contribution of the introduced model is the ability to answer the question defined in the introduction of this article, for which there was no comparable tool available prior to the one introduced in this work. One clear advantage is that the created model can be used without any changes for an arbitrary number of parts and an arbitrary layout of the supply chain. The model allows the allocation scheme for individual parts to be selected and tested. The user can use this to determine how a given allocation scheme will impact the overall output of the supply chain in the modelled period and to potentially compute the ratio of time points in which the supply chain will be located in the individual states.

The proposed model has its limitations that arise from the adopted requirements of the model. The introduced model cannot capture situations where, for example, one of the supplier parts of the chain sends part of its output also outside of the modelled system and can then redirect their production towards the customer in the chain in case of a disruption. Another limitation is the fact that it is not possible to choose different probability distributions (which could potentially be a better model for real-world supply chains) other than the exponential distribution. The possibility of sending part of the production output to a warehouse has a fundamental impact on the consequences of the disruption and the arising reduction of the output for the given part - this is especially true for shorter and less significant disruptions.

There is currently no methodology for determining the frequency of disruptions and their duration. That is why an estimate of the input parameters places significant demands on the user, especially in this area. This can be considered one of the main limitations of the introduced model; however, that being said, the same limitation also applies in general for all current models in the area of supply chain resilience, and so tackling this limitation should be a priority for future research. Even though the abstraction of resilience in the mean duration of the disruption complies with the adopted definition of resilience, this does in fact, represent a fairly prominent limitation. Accepting this prerequisite means that the model cannot faithfully model, e.g., the relationship between individual parts, flexibility, communication and other capabilities of the supply chain. A description of the dependence of improvement/increase of the resilience of individual parts via a linear equation is a significant simplification of the real world, and the same also applies to the use of the cumulative economic output as an indicator of the supply chain's output.

Based on the presented results, it is possible to provide a set of recommendations for future research in the area of building up the resilience of supply chains, supporting decision-making in this field and for the further development of the proposed model. Future research should also focus on removing the limitations of the introduced model specified in the previous subsection and arising from the prerequisites for the validity of the model. In order to increase the expressive power of the model, future extensions to the model should focus on supporting a better representation for the links between individual parts and/or on allowing for variable functional dependencies of increasing resilience on the allocation size. The model should also be expanded with the possibility of working with several types of disruptions, whereas for each disruption, it should be possible to have a separate set of input parameters. One of the aims of future research should also be to determine a good way of incorporating specific capabilities of a supply chain into the introduced model; in particular, it should be possible to set up metrics, functional dependencies for resilience improvement and a subsequent summarized expression of the chain's resilience via a unified index. Such an index would represent a managerial and user-friendly depiction of the modelling results.

\section{Acknowledgement}

The work was supported by the specific university research of Ministry of Education, Youth and Sports of the Czech Republic no. SP 2020/61 and no. SP 2020/60.

\section{References}

[1] BUSINESS CONTINUITY INSTITUTE, BCI Supply Chain Resilience Report 2018, Caversham: BCI, 2018.

[2] CHRISTOPHER, M., PECK, H.: Building the Resilient Supply Chain, International Journal of Logistics Management, Vol. 15, No. 2, pp. 1-13, 2004.

[3] SHEFFI, Y., RICE, J.B.: A Supply Chain View of the Resilient Enterprise, MIT Sloan Management Review, Vol. 47, No. 1, pp. 8-41, 2005. 
MODELLING OF FINANCIAL RESOURCE ALLOCATION FOR INCREASING THE SUPPLY CHAIN RESILIENCE USING MARKOV CHAINS

Martin Čech; Radim Lenort

[4] WORLD ECONOMIC FORUM, Building Resilience in Supply Chains: Report, Switzerland: World Economic Forum, 2013.

[5] PETTIT, T.J.: Supply Chain Resilience: Development of a Conceptual Framework, an Assessment Tool and an Implementation Process, Ohio: Disertation thesis, The Ohio State University, 2008.

[6] SHEFFI, Y., CLOSS, D.J., DAVIDSON, J.: Supply Chain Resilience: How Can You Transcend Vulnerability in Your Supply Chain to Gain Competitive Advantage?, The Official Magazine of the Logistics Institute, Vol. 12, No. 1, pp. 1-30, 2006.

[7] CARVALHO, H., CRUZ-MACHADO, V.: Designing Principles to create Resilient Supply Chains, Proceedings of the 2007 Industrial Engineering Research Conference, Caracas: Catholic University, pp. 186-191, 2007.

[8] ENYINDA, Ch.I., SZMEREKOVSKY, J.: Sense and Respond Supply Chain: A Prescription for Mitigating Vulnerability in the U.S. Pharmaceutical Value Chain, Journal of Global Business Issues, Vol. 2, No. 2, pp. 95-99, 2008.

[9] FALASCA, M., ZOBEL, CH.W., COOK, D.: A Decision Support Framework to Assess Supply Chain Resilience, Proceedings of the $5^{\text {th }}$ International ISCRAM Conference, Washington DC, USA, 2008, pp. 596-605, 2008.

[10]IAKOVOU, E., VLACHOS, D., XANTHOPOULOS, A.: An Analytical Methodological Framework for the Optimal Design of Resilient Supply Chains, International Journal of Logistics Economics and Globalisation, Vol. 1, No. 1, pp. 1-20, 2007.

[11]TANG, Ch.S.: Robust Strategies for Mitigating Supply Chain Disruptions, International Journal of Logistics: Research and Applications, Vol. 9, No. 1, pp. 33-45, 2006.

[12]RIBEIRO, J.P., BARBOSA-POVOA, A.: Supply Chain Resilience: Definitions and Quantitative Modelling Approaches - A literature review,
Computers \& Industrial Engineering, Vol. 115, No. 1, pp. 109-122, 2018.

[13] SNYDER, L.V., ZÜMBÜL, A., PENG, P., RONG, Y., SCHMITT, A.J., SINSOYSAL, B.: OR/MS Models for Supply Chain Disruptions: A Review, IIE Transactions, Vol. 48, No. 2, pp. 89-109, 2016.

[14]Thailand Flooding 2554 Rapid Assessment for Resilient Recovery and Reconstruction Planning, Thailand: Ministry of Finance, Royal Thai Government and The World Bank 18, 2012.

[15] CARVALHO, H., BARROSO, A.P., MACHADO, V.H., AZEVEDO, S., CRUZ-MACHADO, V.: Supply Chain Redesign for Resilience Using Simulation, Computers and Industrial Engineering, Vol. 62, No. 1, pp. 329-341, 2012.

[16]NUNES, I., FIGUEIRA, S., CRUZ-MACHADO, V.: Combining FDSS and Simulation to Improve Supply Chain Resilience, Lecture notes in business information processing, Vol. 121, No. 1, pp. 42-58, 2012.

[17]RICE, J.B. Jr.: Quantifying Supply Chain Resilience, USA: MIT Center for Transportation and Logistics, 2016.

[18]GRAKOVA, E.: Metodika uplatnění počítačové simulace pro řízení odolných dodavatelských řetězců, Ostrava: Disertační práce, Vysoká škola báňská Technická univerzita Ostrava, 2015. (Original in Czech)

[19] KŘIVÝ, I.: Náhodné procesy, Ostrava: Ostravská Univerzita, 2014. (Original in Czech)

[20] KONSTANTOPOULOS, T.: Introductory lecture notes on Markov Chains and Random Walks, Greece: Takis Konstantopoulos, 2009.

[21]KOŘENÁŘ, V.: Stochastické procesy, Praha: Oeconomica, 2010. (Original in Czech)

\section{Review process}

Single-blind peer review process. 